\title{
Brincando de lavar as mãos - um relato de experiência e suas ramificações em tempos de isolamento social
}

\author{
Handwashing game - an experience report and its ramifications in times of pandemic and social \\ isolation
}

Jugar al lavado de manos: un relato de la experiencia y sus ramificaciones en tiempos de aislamiento social

Recebido: 07/12/2021 | Revisado: 12/12/2021 | Aceito: 17/12/2021 | Publicado: 02/01/2022

\author{
Guile Gutfilen Schlesinger \\ ORCID: https://orcid.org/0000-0003-1760-2633 \\ Universidade Federal do Rio de Janeiro, Brasil \\ E-mail: gs.guile@gmail.com \\ Yara Leite Adami \\ ORCID: https://orcid.org/0000-0003-2881-923X \\ Universidade Federal Fluminense, Brasil \\ E-mail: yaraadami@id.uff.br
}

\begin{abstract}
Resumo
No Brasil, e nos demais países em desenvolvimento, parasitoses intestinais constituem grave problema de saúde pública. Crianças em idade pré-escolar merecem atenção especial quanto à questão de infecção por enteroparasitos, já que esse grupo apresenta maior risco de mortalidade para infecções. Ademais, a manutenção da saúde nesta fase é capaz de aumentar as chances de sobrevida na idade escolar e adulta. O presente trabalho objetivou desenvolver atividades lúdicas de prevenção à infecção por enteroparasitos com ênfase na lavagem das mãos com crianças de uma creche comunitária localizada na região oceânica de Niterói, RJ. Através da fala e postura dos infantes, percebe-se que foi desenvolvido o potencial transformador social no sentido de multiplicar informações e questionamentos relacionados aos cuidados com a saúde. Em tempos de pandemia e confinamento, atividades de entretenimento infantil são de grande valia, especialmente por conferirem importante conhecimento que ajuda na prevenção de COVID-19 e tantas outras doenças infecto-contagiosas.
\end{abstract}

Palavras-chave: Parasitismo; Jogos; Lavar as mãos; Educação em saúde.

\begin{abstract}
In Brazil, as in other developing countries, intestinal parasites are a serious public health issue. Preschool children deserve special attention regarding intestinal parasite infection since this group has a higher risk of mortality for several infections. In addition, the healthcare in this age group can increase its chances of reaching school-age and adulthood. This paper aims to develop fun activities to prevent infection by intestinal parasites, especially focusing on hand washing, with children of a daycare placed at Niterói-RJ, inspired by experience exchange. Through the infants comments and behaviour, it was possible to notice that their social transformative potential was developed as they were capable of spreading health care information. In times of pandemic and confinement, children's entertainment activities are of great value, especially when they provide important knowledge that helps preventing COVID-19 and so many other infectious diseases.
\end{abstract}

Keywords: Parasitic diseases; Games; Handwashing; Health education.

\section{Resumen}

En Brasil, como en otros países en desarrollo, los parásitos intestinales son un grave problema de salud pública. Los niños en edad preescolar merecen especial atención con respecto al tema de la infección por enteroparásitos, ya que este grupo tiene un mayor riesgo de mortalidad por diversas infecciones. Además, mantener la salud en este grupo de edad es capaz de aumentar las posibilidades de supervivencia en la edad escolar y adulta. El presente trabajo tuvo como objetivo desarrollar actividades entretenidas para prevenir la infección por enteroparásitos con énfasis en lavarse las manos con niños de una Guardería infantil a la luz del intercambio de experiencias. A través del habla y la postura de los bebés, está claro que el potencial de transformación social se desarrolló en el sentido de multiplicar la información y las preguntas relacionadas con la atención médica. En tiempos de pandemia y confinamiento, las actividades de entretenimiento para niños son de gran valor, especialmente porque proporcionan un conocimiento importante que ayuda a prevenir COVID-19 y muchas otras enfermidades.

Palabras clave: Enfermedades parasitarias; Juegos; Lavarse las manos; Educación en Salud. 


\section{Introdução}

O Referencial Curricular Nacional para a Educação Infantil destaca em seus objetivos gerais que "a prática da educação infantil deve se organizar de modo que as crianças desenvolvam as seguintes capacidades: (...) descobrir e conhecer progressivamente seu próprio corpo, suas potencialidades e seus limites, desenvolvendo e valorizando hábitos de cuidado com a própria saúde e bem-estar" (MEC, 1998).

Para que estes objetivos sejam alcançados, é necessário partir do princípio de que a formação da identidade é construída a partir de experiências e aprendizagens que acontecem no contexto das relações sociais e ambientais desde a mais tenra idade. Assim, crianças trazem consigo conhecimentos, sensibilidades, hábitos e valores antes mesmo de entrarem na creche (Goergen, 2007).

Este conceito pode ser percebido em relação às questões de saúde, como aponta Marcondes (1972), ao ressaltar que uma criança, ao entrar na escola, já traz práticas de saúde que lhe foi ensinada em sua casa. A ausência de bases teóricocientíficas que fundamentem tais atitudes pode tornar necessárias modificações e adaptações dos hábitos trazidos pelos alunos.

Neste sentido, Martins et al., (2007) propõe que a educação em saúde deve ser promovida por meio de diálogo, reflexão, questionamentos e trocas. Isso porque cabe ao público-alvo da ação decidir se os ensinamentos em saúde devem ou não ser incorporados à rotina de cada indivíduo. Desta forma, motiva-se o aprendizado do educando, tornando-o capaz de rever suas práticas baseadas em conhecimento (Marcondes, 1972).

De fato, a Organização Mundial de Saúde (WHO, 2016) verificou que 10.448 .607 indivíduos na faixa etária de 1-14 anos necessitavam de quimioterapia preventiva para infecções por geohelmintos no Brasil e dentre os quais contavam-se 2.897.744 crianças em idade pré-escolar (1-5 anos).

No Brasil, assim como nos demais países em desenvolvimento, parasitoses intestinais constituem grave problema de saúde pública, apresentando variações de acordo com as condições de saneamento básico, nível sócio-econômico, grau de escolaridade, idade e hábitos de higiene (Basso, 2008).

Chieffi e Neto (2003) descrevem enteroparasitoses como indicadores seguros das condições de vida de diferentes comunidades. Isso porque a relação hospedeiro-parasito-ambiente terá influência direta na intensidade e na frequiência com que parasitoses intestinais acometem determinadas regiões. Neste sentido, Pinheiro et al., (1977) destacam a importância de conhecer as peculiaridades das regiões e locais acometidos por determinado parasitismo para adoção de medidas profiláticas e de terapias adequadas.

Desta forma, ressalta-se que o Município de Niterói apresenta Índice de Desenvolvimento Humano Municipal (IDHM) igual a 0,837- o maior do estado do Rio de Janeiro (IBGE, 2020). Em contraste, o município apresenta Índice de Gini $=0,59$, indicando alta concentração de renda. Estes dados destoantes se refletem na frequência de enteroparasitismo nas crianças em idade pré-escolar, como apontam os estudos de Uchôa et. al (2001), Uchôa (2004), Ramos (2006) e Uchôa (2009). Estes autores avaliaram a frequência de enteroparasitos em alunos das creches comunitárias no município de Niterói que atendem à população carente. Foi relatada uma positividade para 55\% das crianças que participaram do estudo de Uchôa et al., (2001) e em outro estudo posterior, Uchôa et al., (2004) evidenciaram positividade parasitária em 61,35\% das crianças. Já Ramos (2006) observou uma freqüência de $42 \%$ de parasitoses intestinais na população estudada enquanto que Uchôa (2009) obteve positividade para enteroparasitos em 51,6\% dos alunos. O trabalho de Leite, Toma e Adami (2014) aponta que a prevalência de infecções por enteroparasitos em instituição de acolhimento de menores na Comunidade Ititioca, Niterói-RJ chegava a $70 \%$ entre as crianças e $44 \%$ entre os funcionários. Já no estudo realizado por Belchior et al. (2021) em 2 comunidades de baixa renda do mesmo município, a detecção de enteroparasitos aconteceu em mais 50\% das amostras coletadas. 
Crianças em idade pré-escolar merecem atenção especial quanto à questão de infecção por enteroparasitos, uma vez que esse grupo apresenta maior risco de mortalidade para diversas infecções. Além disso, a manutenção da saúde nesta faixa etária é capaz de conferir aumento das chances de sobrevida na idade escolar e adulta (Stephenson, Latham, Ottesen, 2001). Postulam Ludwig et al., (1999) que o desconhecimento dos princípios básicos de higiene aliado ao contato intenso com o solo, que funciona como um referencial lúdico, aumenta a exposição das crianças a vários parasitos. Adicionalmente, instalações que mantém crianças em contato próximo - tais como creches - aumentam o risco de contração de doenças infecto-contagiosas nessa população altamente suscetível (Keystone et al., 1978). Isso porque mesmo em ambientes coletivos que possuam condições de higiene satisfatórias, o grande número de usuários em instalações sanitárias não permite, muitas vezes, obedecer às normas de higiene, como observam Chieffi et al., (1974).

Estudo realizado por Belchior (2018; 2021) revela que das 150 amostras fecais coletadas em duas instituições fluminenses de ensino infantil, 80 foram positivas para algum tipo de enteroparasito, o que corresponde a uma prevalência de 53,3\%. Dessa forma, espera-se que desenvolvendo atividades lúdicas de prevenção de enteroparasitismo, seja possível a obtenção de um impacto positivo na reversão deste quadro.

\section{Material e Métodos}

As atividades foram realizadas em uma creche comunitária localizada no Jacaré, a qual funciona nas dependências da Igreja Metodista, na região Oceânica de Niterói. A instituição atende 100 crianças de 2 a 6 anos em horário integral gratuitamente, e a maioria das crianças vivem em áreas de risco. Além das atividades pedagógicas, as crianças recebiam 4 refeições, banho e 2 escovações diárias. Para se manter, a Creche conta com uma parceria entre a AMAS-ITAIPU (Associação Metodista de Ação Social) e a Prefeitura Municipal de Niterói, que é insuficiente para suprir os gastos da instituição. Por isso, a instituição busca constantemente novos parceiros para complementar seus custos. Além do pátio coberto com brinquedos, a instituição conta com refeitório, "escovódromo" - pias adjacentes ao refeitório usadas para lavar as mãos antes das refeições e escovar os dentes depois das mesmas - e aparelho de televisão digital em cada sala.

O turno integral permitiu que houvesse tempo hábil para que cada atividade fosse desenvolvida ao longo do dia. Isso porque a atividade era proposta e executada pela manhã e o conteúdo aprendido era revisto e registrado no período da tarde. Outro ponto importante a ser ressaltado era a presença de televisores em todas as salas de aula. Isso permitiu trabalhar com números menores de alunos durante as exibições dos vídeos o que, por sua vez, facilitou a concentração dos participantes no filme. Além disso, evitava o deslocamento das turmas para o início da atividade. Consequentemente, havia mais tempo para desenvolver o tema proposto e menores chances de dispersar a atenção das crianças ao final da exibição. Trata-se de estudo descritivo, do tipo relato de experiência, acerca de conjunto de atividades educativas realizadas na creche comunitária de 5 a 8 de junho de 2018, com 78 alunos na faixa etária de 3-6 anos divididos em turmas de 18, 15, 22, 15 e 8 alunos, respectivamente (GREI 3 - crianças com 3 anos completados até o mês de agosto; GREI4 A e GREI4 B crianças com 4 anos completados até o mês de agosto, GREI5 A e GREI5 B -crianças com 5 anos completados até o mês de agosto).

As atividades do dia ocorreram de acordo com o esquema abaixo (Quadro 1). 
Quadro 1: Sequência de atividades propostas para lavagem de mãos realizada em Creche Comunitária de Niterói, RJ.

\begin{tabular}{|c|c|}
\hline Atvidade & Objetivo \\
\hline $\begin{array}{l}\text { Reflexões: a) o que precisamos fazer antes de } \\
\text { comer? B) E depois de ir ao banheiro? C) Por quê? }\end{array}$ & $\begin{array}{l}\text { I. Instigar a curiosidade dos participantes acerca do tema; } \\
\text { II. Permitir troca de experiências; } \\
\text { III. Conhecer os hábitos de higiene dos participantes e suas } \\
\text { famílias. }\end{array}$ \\
\hline $\begin{array}{c}\text { Exibição do vídeo "Sid, o cientista: por que lavamos } \\
\text { as mãos?" } 1\end{array}$ & I. Discutir a importância da lavagem das mãos. \\
\hline Roda de conversa sobre o filme & $\begin{array}{l}\text { I. Avaliar o aprendizado acerca do tema; } \\
\text { II. Permitir troca entre os alunos. }\end{array}$ \\
\hline $\begin{array}{l}\text { Experiência proposta pelo vídeo: a) sujar as mãos } \\
\text { com terra b) limpar com papel toalha c) verificar se } \\
\text { a limpeza foi efetiva com o auxílio da lupa d) lavar } \\
\text { as mãos com água e sabão e) verificar se a limpeza } \\
\text { foi efetiva com o auxílio da lupa }\end{array}$ & $\begin{array}{l}\text { I. Trabalhar a forma correta de lavar as mãos; } \\
\text { II. Sensibilizar a respeito das áreas das mãos que são } \\
\text { negligenciadas durante a lavagem; } \\
\text { III. Estimular a investigação do problema e da sua solução; } \\
\text { IV. Oportunizar contato com lupa. }\end{array}$ \\
\hline Registro da atividade & I. Avaliar o aprendizado acerca do tema. \\
\hline
\end{tabular}

Fonte: Autores.

Antes de iniciar a animação, a facilitadora perguntou ao grupo: “Quando devemos lavar as mãos? Por quê?” Depois de responderem livremente e dividirem suas experiências e relatos, cada turma assistiu ao vídeo proposto em sua sala. Em seguida, cada turma foi encaminhada ao pátio para dividir o que aprendeu. Seguindo o experimento proposto pelo vídeo, foram colocados no pátio um recipiente plástico com terra, um rolo de papel toalha e um recipiente plástico com água e detergente (Figura 1). A atividade também contava com lupas. Individualmente, cada discente sujou bastante as mãos com terra e tentou limpá-las apenas com papel toalha até ficarem aparentemente limpas. Com o auxílio da lupa, as crianças deveriam avaliar se a limpeza foi efetiva.

Em seguida, usaram o tonel com água e sabão para lavar de forma eficiente as mãos e, com o auxílio da lupa, avaliar se dessa vez as mãos estavam limpas. No período da tarde, cada turma registrou a atividade na forma de cartaz que reproduzia a fala dos participantes (Figura 2).

\footnotetext{
${ }^{1}$ Desenho infantil criado e produzido pela The Jim Henson Company e KCET. Esta animação é feita em CGI, apresenta cenas em live-action e Animação em Flash. Neste episódio de $12 \mathrm{~min}$. e $12 \mathrm{seg}$, Sid, um menino de 4 anos muito curioso, procura entender por que ele deve sempre lavar as mãos. Com a ajuda de uma experiência na escola,Sid aprende que os microorganismos são muito pequenos para serem vistos a olho nu e que lavar as mãos com sabão o protegerá contra os "germes", especialmente contra aqueles do resfriado do seu pai.
} 
Figura 1 - Material utilizado na atividade proposta pelo vídeo "Sid, o cientista: por que lavamos as mãos?"

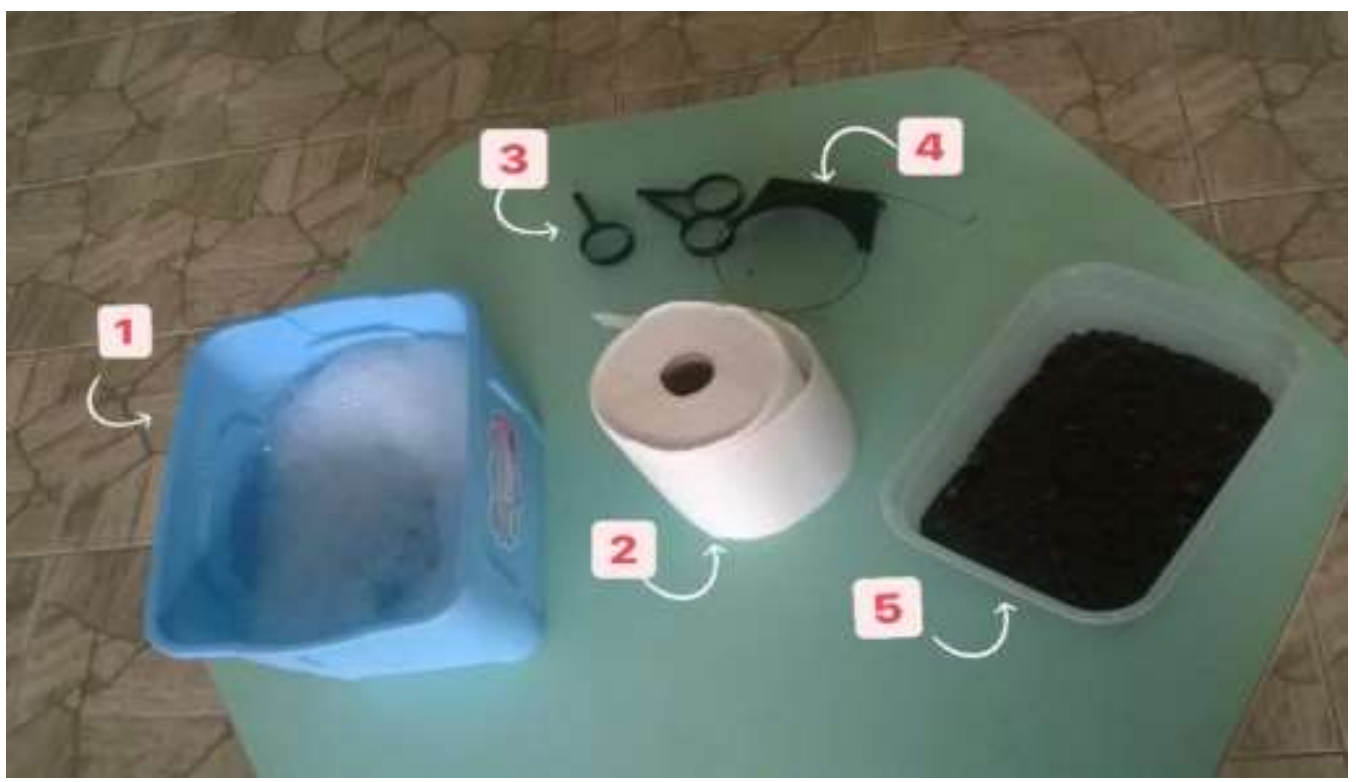

1 - recipiente com água e detergente, 2 - rolo de papel toalha, 3 - lupas, 4 - óculos com lentes de aumento, 5 - recipiente plástico com terra. Fonte: Autores.

O trabalho foi aprovado pelo Comitê de Ética em Pesquisas com Seres Humanos da Faculdade de Medicina da UFF, Parecer $\mathrm{n}^{0} 3.326 .585$.

\section{Resultados}

Os participantes responderam de forma entusiasmada às reflexões propostas antes da exibição do filme. Além disso, as crianças demonstraram estar familiarizadas com a importância de lavar as mãos antes das refeições e depois de irem ao banheiro. Quando questionadas sobre os motivos, falaram sobre a sujeira, sobre os "germes pequeninhos" e bactérias. Além disso, as crianças relataram espontaneamente comportamentos cotidianos que contribuem para a perpetuação dos ciclos parasitológicos. Alguns alunos das turmas GREI 5A e GREI 5B já conheciam o desenho animado apresentado e ficaram muito contentes em descobrir que assistiriam a ele. Os demais colegas de turma mostraram-se muito curiosos ao ouvirem os amigos relatando que "esse desenho é muito legal!".

Uma demonstração de entusiasmo pode ser percebida quando os participantes pediram que o vídeo fosse exibido mais de uma vez. Quando convidadas a dividir o que aprenderam com a exibição do filme, os discentes reproduziram algumas técnicas que devem ser usadas durante a lavagem de mão, como a importância de lavar entre os dedos.

Durante a experiência proposta pelo vídeo "Sid, o cientista - por que lavamos as mãos?", os participantes colocaram o que aprenderam em prática. Isso porque as crianças eram estimuladas a buscar com as lupas restos de terra entre seus dedos e em suas unhas além das palmas e dorsos das mãos. Os participantes mostraram-se muito curiosos e entusiasmados com o uso da lupa. Mesmo depois das mãos estarem limpas, as crianças continuaram dispostas a brincar com a ferramenta.

A aluna V. (5) ao investigar as unhas falou para a pedagoga que auxiliava na atividade: "Tia, não sai [esse resto terra]. Me ajuda?" e a profissional respondeu "Vamos pedir pra mamãe deixar as unhas sempre curtinhas pra isso não acontecer de novo, tá?". A fala da criança demonstra que ela percebeu a importância de manter as mãos e unhas limpas. Além disso, a situação pode sensibilizar os responsáveis com relação a relevância de aparar as unhas das crianças. 
O cartaz de registro elaborado pelos alunos da turma GREI5 A indica que a experiência foi memorável para os mesmos, posto que lembraram de todas as etapas da tarefa. Percebe-se que o desenho animado ficou igualmente na memória dos participantes quando mencionam que são "bichinhos verdes e pequeninhos" conforme mostra a imagem do filme (Figura 2).

Figura 2 - Registro da atividade proposta pelo filme "Sid, o cientista - por que lavamos as mãos?"
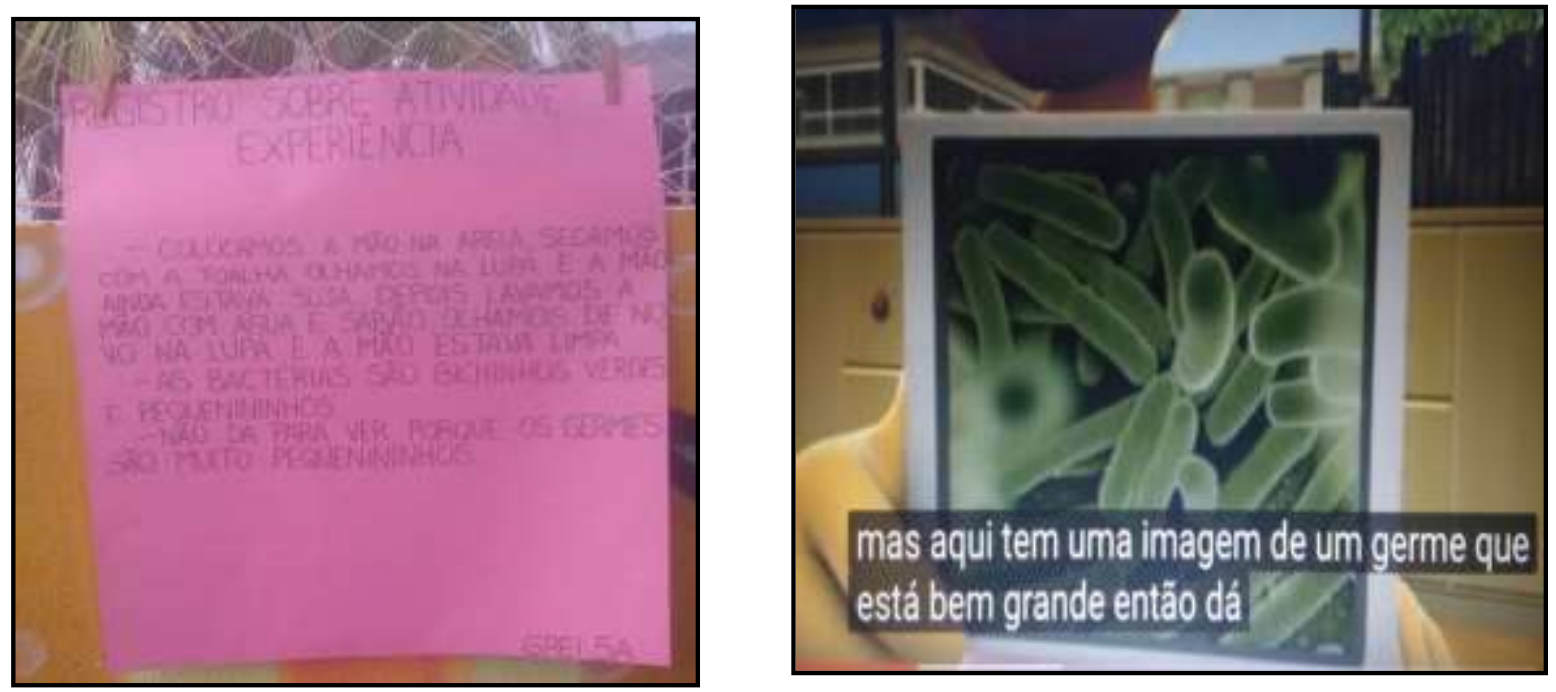

À direita cartaz com o registro sobre a atividade experiência: "Colocamos as mãos na areia e secamos com a toalha, olhamos na lupa e a mão estava suja depois lavamos a mão com água e sabão, olhamos de novo a lupa e a mão estava limpa; as bactérias são bichinhos verdes e pequenininhos; não dá pra ver porque os germes são muito pequenininhos"; à esquerda: cena do filme "Sid, o cientista - Por que lavamos as mãos?" descrita no "registro (esquerda). Fonte: Autores.

\section{Discussão}

A alfabetização em saúde pode ser uma consequência natural da alfabetização tradicional e é vista atualmente como pilar essencial para avanços na área, tanto em adultos quanto em crianças, quando associada à promoção e educação em saúde (Resende \& Figueiredo, 2018). À luz de Freire et al. (2009) sugere que a partir dos 3 anos os indivíduos são capazes de desenvolver as habilidades necessárias para atingir a literacia em saúde. Adicionalmente, é ressaltada a importância do material utilizado nesta alfabetização ser adequado para a idade, para o contexto cultural e social do sujeito. Para Pizarro e Lopes Jr. (2016), por sua vez, não existe limite de idade e nem mesmo de escolaridade para a alfabetização científica.

No entanto, quando se trata da inclusão do ensino de ciências ${ }^{2}$ nos anos iniciais, ainda não há recurso didático suficiente para que o professor se sinta contemplado (Jacob et al., 2017). Os materiais didáticos são produtos pedagógicos utilizados na educação com fins didáticos que visam auxiliar, facilitar, incentivar ou possibilitar o processo de aprendizagem, proporcionando o desenvolvimento, a melhoria do raciocínio e do senso crítico, o despertar da curiosidade e o interesse dos alunos acerca do objeto de estudo (Souza \& Messeder, 2018). Assim sendo, é possível afirmar que todo o material empregado e desenvolvido no projeto pode ser considerado didático pois cumpre as funções acima citadas.

Pensando na carência de material didático adequado observada pelos autores Jacob et al. (2017), o levantamento e uso de desenhos animados educativos e experiência de lavagem de mãos podem ser de grande valia como aparato educativo e possibilitam usos em diferentes atividades de ensino, recreação ou mesmo para replicação dos exercícios propostos nos anos vindouros.

${ }^{2}$ Como já evidenciado por Serra et al., (2013), a alfabetização em saúde no contexto escolar acaba sendo inserida como parte da alfabetização científica. 
Em relação ao uso de desenho animado, Jacob et al. (2017) veem nesse recurso audiovisual uma dimensão educativa. Esta ferramenta, segundo os autores, pode ser um bom material pedagógico já que na educação infantil as crianças trazem para o ambiente escolar o que conheceram durante os programas de televisão. A familiaridade com a animação "Sid, o cientista" demonstrada por alguns alunos da Creche onde foi realizado o estudo, facilitou o andamento da atividade já que os mesmos se mostraram entusiasmados e emanaram esta empolgação para o restante do grupo.

Os relatos espontâneos a respeito de hábitos que perpetuam ciclos parasitológicos podem ser vistos como indicadores de alfabetização científica conforme proposto por Pizarro e Lopes Jr. (2015). Esses pesquisadores definem uma série de indicadores dentre eles "articular ideias" e "atuar". O primeiro trata da capacidade do discente relacionar conhecimento teórico, a sua realidade e o meio-ambiente, enquanto o segundo está relacionado à autopercepção do discente como agente transformador e a tornar-se um multiplicador dos debates vividos no ambiente escolar, na sociedade em que está inserido. Assim, quando a criança relata determinados comportamentos de seus cuidadores e os percebe como risco à contração de enteroparasitismo, pode-se afirmar que houve articulação de ideias. Embora crianças de tão tenra idade possivelmente não apresentem maturidade ou bagagem suficiente para desenvolver um debate ou questionamento, é possível afirmar que as mesmas se viram como agentes transformadores ao replicar o conhecimento adquirido para seus responsáveis e colegas. Tal resultado concorda com o que Serra et al., (2013) supunham acerca do conhecimento concatenado ao contexto social da criança. Estes pesquisadores já previam que contextualizar informações de enfermidades infecto-parasitárias de caráter zoonótico além de favorecer a troca experiências relacionadas ao seu cotidiano poderia levar o aluno a se sentir protagonista do processo de prevenção, desenvolvendo assim, o interesse em tornar-se um agente multiplicador desse conhecimento.

No sentido da troca de experiência previsto pelos autores, pode-se perceber que as reflexões propostas antes das exibições dos filmes, bem como aquelas propostas antes, durante, e depois de cada atividade foram oportunidades formais estabelecidas para que tal troca de experiência ocorresse. Porém, ao longo do dia de acordo com os acontecimentos cotidianos, os relatos tornaram-se cada vez mais espontâneos e passaram a fazer parte das conversas das crianças.

Muito além de tornar o aluno um potencial transformador de seu convívio social, relatar o que foi aprendido ao seu cuidador, assim como exibir os trabalhos concluídos no pátio das instituições, trouxe os responsáveis para mais perto da educação dos menores. E, muito embora certos responsáveis deleguem a função educadora para a escola ou creche de forma exclusiva, as bases educativas familiares devem ser desenvolvidas em conjunto com os saberes da creche e/ou escola, exigindo responsabilidades específicas, mas não excludentes, de cada uma das partes. A corresponsabilidade tornou-se ainda mais notória na experiência de lavagem de mãos: uma das participantes percebeu que, apesar de ser constantemente instruída a lavar as mãos e ter aprendido a técnica correta para fazê-lo, não conseguiria executá-la com eficiência sozinha porque estava com as unhas longas e houve acúmulo de sujidade subungueal. Cabe citar que de acordo com a pesquisa realizada por Seidel et al., (2016) em uma creche em São Miguel do Oeste - SC foi demonstrado que 5\% das amostras subungueais coletadas foram positivas para enteroparasitos. Evidencia-se, portanto, que “a necessidade de orientação dos pais também é reconhecida”. Adicionalmente, “a participação dos profissionais de saúde na disseminação de conhecimento sobre prevenção e controle de doenças transmissíveis é importante e necessária" (Serra et al. 2013).

Ademais, em sua revisão de literatura, Vasconcelos e Silva-Vasconcelos (2021) apontam que a promoção da saúde também está fundamentada na capacidade decisória que só pode ser exercida de maneira plena a partir do conhecimento dos processos que envolvem o eixo saúde-doença. Para tal, a saúde deve ser entendida como um produto social, moldada por eventos diversos. Dessa forma, a educação em saúde se torna uma das ferramentas essenciais na prevenção e controle das parasitoses intestinais, mas que não pode ser restringida ao nível individual. E, adicionalmente, pode encontrar ramificações em tempos de pandemia e isolamento social. "Embora as crianças não sejam a face desta pandemia, seus impactos maiores nas crianças são catastróficos e é uma das consequências mais duradouras para as sociedades como um todo” (ONU, 2020). 
A forma como a criança é mantida em um ambiente restrito durante o isolamento social pode causar danos aos cuidados e vínculos necessários para a qualidade do crescimento saudável e do desenvolvimento infantil nos aspectos físicos e sócioafetivos. Entre as incógnitas em torno da atual pandemia de COVID-19 está o tempo que as famílias precisarão ficar em casa.

Para muitos, ficar em casa é uma demanda sem precedentes. Creches, escolas, esportes, clubes, encontros de brincadeiras e festas que normalmente ocupavam os membros da família deixam de fazer parte de suas rotinas. Além disso, o modelo "home office" adotado em diversas ocupações aliado ao fechamento das escolas e creches leva ao rearranjo do ambiente físico para acomodar as demandas de trabalho, estudo e brincadeiras A nova dinâmica resulta em sobrecarga de trabalho doméstico. Também existem famílias que enfrentam instabilidade no emprego, desemprego e problemas financeiros. Além disso, as crianças e seus pais estão mais desconectados de seus sistemas de apoio direto como membros da família que não habitam na mesma casa, grupos religiosos e outras organizações comunitárias, e, por isso, podem experimentar muitos riscos e desafios. Neste sentido, o confinamento das crianças com suas famílias em todos os momentos as priva da experiência normal na aprendizagem, socialização e atividade física e também desafia os pais e/ou responsáveis a ocupar o tempo de seus filhos com atividades que promovam a saúde e o bem-estar emocional. A educação à distância torna-se especialmente preocupante no âmbito da Educação Infantil, uma vez que neste modelo o aluno é privado de relações proximais, ambiente coletivo compartilhado e experiências concretas.

Pode-se observar que esses novos desafios estão muitas vezes potencializando os problemas existentes previamente no contexto familiar, especialmente naquelas que apresentam maior vulnerabilidade psicossocial por viverem em condições adversas com múltiplos fatores de risco. $\mathrm{O}$ aumento dos casos de violência doméstica durante o distanciamento social reflete o agravo das adversidades que põem em cheque o desenvolvimento saudável da criança (Linhares \& Enumo, 2020).

Dúvidas sobre a doença em si, sobre a duração do isolamento e a constante ameaça da morte explorada via mídia e reproduzida constantemente pelos membros do núcleo familiar aliados a um clima de animosidade familiar, aumentam o estresse na população infantil já que transforma um ambiente de acolhimento em um lugar de incertezas. Destacam-se nesse sentido questões mais graves como a potencialização de problemas prévios no ambiente doméstico como o abuso infantil e negligência. Isso porque o estresse dos responsáveis pode ser um grande preditor para o abuso e agressividade direcionada aos menores. Neste segmento, nota-se a perpetuação da violência familiar que pode ocorrer devido às vivências nos anos iniciais do desenvolvimento. Além dos desafios inerentes ao isolamento, existem as importantes tarefas de manutenção do autocuidado e de garantir que os menores estejam preparados para a pandemia de longo prazo, sem contudo alarmá-los (Linhares \& Enumo, 2020); (Buheji et al., 2020); (Szabo et al., 2020).

É devido a este clima de tensão e ansiedade que a UNICEF (2020) recomenda diálogos abertos com as crianças para que elas possam entender, lidar e até mesmo contribuir de forma positiva com a situação. Para isso, a organização recomenda partir do que a criança já conhece para trabalhar o assunto e dar início à discussão ou desenvolver estratégias empregando jogos, desenhos e histórias para o mesmo fim. A instituição reforça ainda a importância de adequar o diálogo à idade do infante e recomenda prestar atenção à ansiedade que o assunto possa trazer. No caso de crianças muito pequenas, reforçar as práticas de higiene sem estimular novos medos é suficiente (UNICEF, 2020).

Levando em conta essas recomendações, é possível dizer que a prática descrita neste relato de experiência pode ser adaptada à realidade de diferentes famílias. Isso porque o material utilizado pode ser facilmente encontrado nas casas de diferentes famílias brasileiras para reproduzir a atividade. Segundo os últimos dados do IBGE (2020), a internet está presente em 79,1\% dos lares brasileiros, o que significa que a animação disponível de forma gratuita na plataforma YouTube pode ser acessada por parte significativa dos lares. Os demais materiais como terra, papel toalha, água e sabão também são de baixo custo. Caso não haja acesso à terra, materiais como farináceos, borra de café ou carvão triturado podem ser excelentes substitutos. O mesmo vale para papel higiênico e guardanapos em relação ao papel-toalha. Já a lupa pode ser substituída por 
lentes de aumento, óculos - usados como uma lente de aumento sob a supervisão de um adulto para evitar acidentes - ou mesmo construídas em casa como mais uma sugestão de atividade de entretenimento.

A reprodução em domicílio poderia funcionar como reforço para os conhecimentos adquiridos por crianças que já participaram da atividade ou mesmo como iniciativa dos pais e cuidadores para entreter, discutir e reforçar hábitos de higiene. Em qualquer um dos casos, crianças de diferentes idades que vivem no mesmo lar tem a oportunidade de vivenciar esta experiência, e ainda repassar os conhecimentos para os responsáveis que coabitam e ainda aprimorar as técnicas de lavagem de mãos. Em tempos de pandemia e confinamento, atividades de entretenimento infantil são de grande valia, especialmente por conferirem importante conhecimento que ajuda na prevenção de COVID-19 e tantas outras doenças parasitárias e infectocontagiosas.

\section{Considerações Finais}

Foi possível desenvolver atividades lúdicas de prevenção à infecção por enteroparasitos com ênfase na lavagem das mãos em Creche Comunitária localizada na Região Oceânica de Niterói, RJ. Houve também sensibilização dos docentes e da direção da instituição sobre os ciclos de vida dos enteroparasitos.

Através da fala e postura dos infantes, percebe-se que foi desenvolvido o potencial transformador social no sentido de multiplicar informações e questionamentos relacionados aos cuidados com a saúde.

Estudos serão necessários para acompanhamento dos impactos dessa intervenção a longo prazo. Seria de grande valia prover estudo clínico para avaliar o impacto real da ação na redução das infecções por enteroparasitos. Destaca-se, no entanto, a limitação de ações pontuais para a prevenção das enteroparasitoses, uma vez que o problema de saneamento básico, tratamento e prevenção é sistêmico.

\section{Agradecimentos}

Agradecimentos: À direção, docentes e funcionários da Creche onde foi realizado o estudo pela parceria durante a execução do projeto. Aos pais das crianças que tanto confiaram e apoiaram esse trabalho.

Suporte Financeiro: Pró Reitoria de Extensão (PROEX) - Universidade Federal Fluminense.

Conflito de interesses: não há.

\section{Referências}

Basso, R. M. C., Silva-Ribeiro, R. T., Soligo, D. S., Ribacki, S. I., Callegari-Jacques, S. M., \& Zoppas, B. C. D. A. (2008). Evolução da prevalência de parasitoses intestinais em escolares em Caxias do Sul, RS. Revista da Sociedade Brasileira de Medicina Tropical, 41(3), 263-268. https://doi.org/10.1590/s0037-86822008000300008

Belchior V.L.R. (2018). Estudo de prevalência de enteroparasitismo em crianças e moradores de duas comunidades carentes do município de Niterói-RJ. (Dissertação de Mestrado). https://app.uff.br/riuff/bitstream/1/7903/1/Vera lucia reis belchior dissertaçao.pdf

Belchior, V. L. R., Toma, H. K., Batista, K. M., Bernarde, K. I. D. S., de Carvalho, L. G., Pilotto, T. P., Adami, Y. L., \& Xavier, A. R. (2021). Predominance of Blastocystis spp, entamoeba histolytica /e.dispar and other protozoan evaluated through classical and molecular diagnostic techniques in two communities of Niterói-rj/Brazil. / Predominância de Blastocystis spp, entamoeba histolytica /e.dispar e outros protozoários avaliados através de técnicas de diagnóstico clássico e molecular em duas comunidades de Niterói-rj/Brazil. Brazilian Journal of Health Review, 4(3), 11741-11754. https://doi.org/10.34119/bjhrv4n3163

Borzekowski D. L. (2009). Considering children and health literacy: a theoretical approach. Pediatrics, 124 Suppl 3, S282-S288. https://doi.org/10.1542/peds.2009-1162D

Buheji, M., Hassani, A., Ebrahim, A., da Costa Cunha, K., Jahrami, H., Baloshi, M., \& Hubail, S. (2020). Children and Coping During COVID-19: A Scoping Review of Bio-Psycho-Social Factors. International Journal of Applied Psychology, 10(1), 8-15. https://doi.org/10.5923/j.ijap.20201001.02

Chieffi, P. P., Moretti, I. G., Nakagawa, E., Gomes, A. D. C., \& Foizer, A. C. M. (1974). Contribuição ao estudo da história natural de enteroparasitoses em uma comunidade fechada 1: Prevalência de enteroparasitos em uma comunidade fechada. Revista da Sociedade Brasileira de Medicina Tropical, 8(1), 41-44. https://doi.org/10.1590/s0037-86821974000100006 
Goergen, P. (2007). Educação moral hoje: cenários, perspectivas e perplexidades. $\quad$ Educ. $\quad$ \& $\quad$ Soc. $28 \quad$ (100). http://www.scielo.br/scielo.php?script=sci_arttext\&pid=S0101-73302007000300006\&lng=pt\&tlng=pt

IBGE - Instituto Brasileiro de Geografia e Estatística (2020). Cidades@/Rio de Janeiro/Niterói/Panorama. https://cidades.ibge.gov.br/brasil/rj/niteroi/panorama.

Jacob, T.D.S.G., Maia, E.D., \& Messeder, J.C. (2017). Desenhos animados como possibilidades didáticas para ensinar conceitos químicos nos anos iniciais. Revista de Ensino de Ciências e Matemática, 8(3): 61-77. https://doi.org/10.26843/rencima.v8i3.1135

Keystone, J. S., Krajden, S., \& Warren, M. R. (1978). Person-to-person transmission of Giardia lamblia in day-care nurseries. Canadian Medical Association journal, 119 (3), 241-248. http://www.ncbi.nlm.nih.gov/pubmed/679128

Leite, R.O., Toma, H.K. \& Adami, Y.L. (2014). Diagnóstico parasitológico e molecular deenteroparasitos entre crianças residentes e funcionários de uma institução beneficente para menores no município de niterói-rj, brasil. Revista de Patologia Tropical, 43(4): 446-458. https://www.revistas.ufg.br/iptsp/article/view/33609/17791

Linhares, M. B. M., \& Enumo, S. R. F. (2020). Reflexões baseadas na Psicologia sobre efeitos da pandemia COVID-19 no desenvolvimento infantil. Estudos de Psicologia (Campinas), 37. https://doi.org/10.1590/1982-0275202037e200089

Ludwig, K. M., Frei, F., Alvares Filho, F., \& Ribeiro-Paes, J. T. (1999). Correlação entre condições de saneamento básico e parasitoses intestinais na população de Assis, Estado de São Paulo. Revista da Sociedade Brasileira de Medicina Tropical, 32(5), 547-555. https://doi.org/10.1590/s003786821999000500013

Marcondes, R. S. (1972). Educação em saúde na escola. Rev. Saúde Publica. 6, 89-96. https://www.scielo.br/pdf/rsp/v6n1/10.pdf

Martins, J. J., Albuquerque, G. L., Nascimento, E. R. P., Barra, D. C. C., Souza, W. G. A. \& Pacheco, W. N. S. (2007). Necessidades de educação em saúde dos cuidadores de pessoas idosas no domicílio. Texto \& Contexto - Enferm. 16(2). http://www.scielo.br/scielo.php?script=sci_arttext\&pid=S0104$07072007000200007 \& \operatorname{lng}=\mathrm{pt} \& \operatorname{lng}=\mathrm{pt}$

MEC - Ministério da Educação e do Desporto (1998). Referenciais Curriculares Nacionais para a Educação Infantil. Brasília: MEC/SEF, 1, 2 e 3. http://portal.mec.gov.br/seb/arquivos/pdf/rcnei_vol 1.pdf

Neto, V. A. \& Chieffi, P. P. (2003). Vermes, verminose a saúde pública. Ciência Cult. 55(1), 41-43.http://cienciaecultura.bvs.br/pdf/cic/v55n1/14854.pdf

Pinheiro, M. D. F. D. S., Marzochi, M. C. D. A., Giugliano, R., \& Giuliano L. G. (1977). Enteroparasitoses em uma comunidade fechada. I - Estudo do solo como elo de transmissão em um orfanato de Manaus, Amazonas, Brasil. Acta Amazonica, 7(4):503-506. https://doi.org/10.1590/1809-43921977074503

Pizarro, M. V., \& Junior, J. L. (2016). Indicadores de alfabetização científica: uma revisão bibliográfica sobre as diferentes habilidades que podem ser promovidas no ensino de ciências nos anos iniciais. Investigações Em Ensino de Ciências, 20(1), 208. https://doi.org/10.22600/15188795.ienci2016v20n1p208

Ramos, G. C. S. C. (2006). Correlação entre parasitoses intestinais, estado nutricional, condições socioeconômicas e sanitárias de crianças de três creches públicas do município de Niterói. (Dissertação de Mestrado) http://www.bdtd.ndc.uff.br/tde_arquivos/33/TDE-2006-09-22T134425Z-378/Publico/UFF-MedDissert-GloriaRamos.pdf

Resende, A., \& Figueiredo, M. (2018). Práticas de literacia familiar: uma estratégia de educação para a saúde para o desenvolvimento integral da criança. $\begin{array}{lllll}\text { Portuguese Journal } & \text { Health, } & 36(2), & 102-113 . & \text { https://doi.org/10.1159/000492265 }\end{array}$

Seidel, L., Mallmann, B. L. K., Tonini, C. R. de A., Cortellini Landivar, E. E., Daiprai, T. M., \& Vidigal, T. M. A. (2016). Parasitas intestinais no conteúdo subungueal de crianças matriculadas em uma creche de são miguel do oeste. Unoesc \& Ciência - ACBS, 7(2), 181-188, https://portalperiodicos.unoesc.edu.br/acbs/article/view/12018

Serra, H., Serra, L. M. M., Lima, R. L., Madeira, N. G., Silva, S. M., Silva, L. H. A. \& Mauad, J. R. C. (2013). Ensino de Ciências e Educação para a Saúde: uma proposta de abordagem. Editora UFGD. https://doi.org/10.1590/1809-43921977074503

Souza, E. M. \& Messeder, J. C. (2018). Deu ciência na costura: Modelo celular didático artesanal. Ensino, Saúde e Ambiente, 11(2):80-101. https://doi.org/10.22409/resa2018.v11i2.a21292

Stephenson, L., Latham, M., \& Ottesen, E. (2000). Malnutrition and parasitic helminth infections. Parasitology, 121(S1), S23-S38. https://doi.org/10.1017/s0031182000006491

Szabo, T.G., Richling, S., Embry, D.D., Biglan, A. \& Wilson, K.G. (2020). From Helpless to hero: promoting Values-Based Behavior and Positive family Interaction in the Midst of COVID-19. Behav Analysis Practice 13, 568-576. https://doi.org/10.1007/s40617-020-00431-0

Uchôa, C. M. A., Lobo, A. G. B., Bastos, O. M. P. \& Matos, A. D. (2001). Parasitoses intestinais: prevalência em creches comunitárias da cidade de Niterói, Rio de Janeiro. Rev. Inst. Adolfo Lutz, 11: 97-101. http://www.ial.sp.gov.br/resources/insituto-adolfo-lutz/publicacoes/rial/2000/rial60_2_completa/898.pdf

Uchôa, C. M. A., Albuquerque, M. C., Bastos, O. M. P., Silva, D. G., \& Silva, P. (2004). Enteroparasitoses em Crianças de Creche. Congr. Bras. de Extensão Univ. Belo Horiz.2004, SA 372-380. https://www.ufmg.br/congrext/Saude/Saude80.pdf

Uchôa, C. M. A., Albuquerque, M. C., Carvalho, F. M., Falcão, A. O., Silva, P. D., \& Bastos, O. M. P. (2009). Parasitismo intestinal em crianças e funcionários de creches comunitárias da cidade de Niterói-RJ, Brasil. Revista de Patologia Tropical, 38(4). https://doi.org/10.5216/rpt.v38i4.8590

UNICEF (2020). How to talk to your child about coronavirus disease 2019 (COVID-19) | UNICEF https://www.unicef.org/coronavirus/how-talk-your-childabout-coronavirus-covid-19. 
Research, Society and Development, v. 11, n. 1, e5811124476, 2022

(CC BY 4.0) | ISSN 2525-3409 | DOI: http://dx.doi.org/10.33448/rsd-v11i1.24476 United Nations (2020). Policy Brief: The Impact of $\quad$ COVID-19 on children https://unsdg.un.org/sites/default/files/2020-
4/160420_Covid_Children_Policy_Brief.pdf

Vasconcelos, W. C., \& Silva-Vasconcelos, A. D. (2021). Ações de educação em saúde como estratégia de prevenção e de controle das parasitoses intestinais: um estudo de revisão sistemática da literatura. Research, Society and Development, 10(11). https://doi.org/10.33448/rsd-v10i11.19301

WHO (2016). Soil-trasmitted helminthiases: Number of children (Pre-SAC and SAC) requiring preventive chemotherapy for soil-transmitted helminthiases. https://apps.who.int/neglected_diseases/ntddata/sth/sth.html 